OPEN ACCESS

Edited by:

Xihui Shen,

Northwest A\&F University, China

Reviewed by:

Stephanie Rochelle Shames, Kansas State University, United States

Christian Rueter,

Universitätsklinikum Münster,

Germany

*Correspondence:

Chengsong Wan

gzwcs@smu.edu.cn

Specialty section:

This article was submitted to

Infectious Diseases,

a section of the journal

Frontiers in Microbiology

Received: 31 August 2018 Accepted: 05 November 2018 Published: 22 November 2018

Citation:

Hua Y, Yan K and Wan C (2018) Clever Cooperation: Interactions

Between EspF and Host Proteins.

Front. Microbiol. 9:2831

doi: 10.3389/fmicb.2018.02831

\section{Clever Cooperation: Interactions Between EspF and Host Proteins}

\author{
Ying Hua ${ }^{1,2}$, Kaina Yan ${ }^{1,2}$ and Chengsong Wan ${ }^{1,2 *}$ \\ ${ }^{1}$ Department of Microbiology, School of Public Health, Southern Medical University, Guangzhou, China, ${ }^{2}$ Key Laboratory of \\ Tropical Disease Research of Guangdong Province, Guangzhou, China
}

EspF is a central effector protein of enterohemorrhagic Escherichia coli (EHEC), enteropathogenic E. coli (EPEC), and Citrobacter rodentium (CR) that is secreted through the type III secretion system to host cells. The interaction between EspF and host proteins plays an important role in bacterial pathogenesis. EspF protein binds to host SNX9 and N-WASP proteins to promote the colonization of pathogenic bacteria in intestinal epithelial cells; combines with cytokeratin 18, actin, 14-3-3ร, Arp2/3, profilin, and ZO-1 proteins to intervene in the redistribution of intermediate filaments, the rearrangement of actin, and the disruption of tight junctions; acts together with Abcf2 to boost host cell intrinsic apoptosis; and collaborates with Anxa6 protein to inhibit phagocytosis. The interaction between EspF and host proteins is key to the pathogenic mechanism of EHEC and EPEC. Here, we review how EspF protein functions through interactions with these 10 host proteins and contributes to the pathogenicity of EHEC/EPEC.

Keywords: EPEC, EHEC (enterohaemorrhagic E. coli), EspF, protein interactions, bacterial pathogenesis

\section{INTRODUCTION}

Over the last decade, the advancing field of cellular microbiology has provided a glimpse of the complex interactions between many bacteria and eukaryotic cells (Hartland and Richardson, 2016). One of the frontiers in this research is the battle between gram-negative enteric bacteria and certain host cells (Poulin and Chamaillard, 2017). Enteropathogenic Escherichia coli (EPEC), enterohemorrhagic E. coli (EHEC), and Citrobacter rodentium (CR) create unique histological lesions in intestinal epithelial cells and are called attaching and effacing pathogens (A/E pathogens) (Gaytán et al., 2016). EHEC and EPEC are a main cause of human disease (Wong et al., 2011). EPEC is the leading pathogen causing diarrhea in infants and young children (Donnenberg and Finlay, 2013), and acute renal failure and hemolytic uremic syndrome caused by EHEC are a source of mortality worldwide (Nguyen and Sperandio, 2012). CR is a mouse-restricted pathogen that shares several pathogenic mechanisms with EHEC and EPEC (Collins et al., 2014). These bacteria colonize the gut mucosa, mainly causing host diarrhea and colitis, even severe diarrhea, but their exact pathogenesis is still unknown.

$\mathrm{EspF}$ is one of the most important virulence factors of $\mathrm{A} / \mathrm{E}$ pathogens, and its domain architecture and function have attracted considerable attention. It is injected into host cells through the type III secretion system (T3SS), targets host mitochondria and the nucleolus (Nougayrède and Donnenberg, 2004; Dean et al., 2010), disrupts tight junctions (Weflen et al., 2010), inhibits phagocytosis (Danika et al., 1999), induces characteristics of hemorrhagic enteritis such as the disappearance of microvilli in intestinal epithelial cells, cytoskeletal rearrangement, mitochondrial 
dysfunction, and apoptosis (Maddocks et al., 2013; Zhao et al., 2013). Mice infected with the espF mutant of CR show intestinal colonization reduction and colonic hyperplasia (Deng et al., 2004; Mundy et al., 2004), and rabbits infected with the EHEC espF mutant exhibit accumulation of polymorphonuclear leukocytes in colonic mucosa (Ritchie and Waldor, 2005). These studies indicate that EspF can promote pathogen colonization and modulate host inflammatory responses by suppressing or reducing host cytokines. Infection with the EPEC espF mutant fails to induce microvillous elongation, which occurs during normal infection, indicating a potential role for EspF in remodeling the brush border (Muza-Moons et al., 2004; Shaw et al., 2005). Moreover, the espF mutant impairs EPEC's ability to kill host cells, suggesting that EspF can induce host cell death (Crane et al., 2001). EspF has hence emerged as the "Swiss army knife" of EHEC/EPEC infection and pathopoiesis (Holmes et al., 2010). In addition, EspF can also exert biological effects by binding to host proteins. It cooperates with SNX9 and N-WASP proteins to promote the colonization of pathogens (Alto et al., 2007; Weflen et al., 2010); communicates with cytokeratin 18 (CK18), actin, 14-3-3̧, Arp2/3, profilin, and zonula occludens1 (ZO-1) proteins; disrupts tight junctions by redistributing intermediate filament protein CK18 and rearranging the actin cytoskeleton (Viswanathan et al., 2004a; Peralta-Ramírez et al., 2008); and interacts with Abcf2 to promote cell apoptosis (Nougayrède et al., 2007). Naturally, the capacity of EspF to affect host proteins is decisive in the pathogenesis of EHEC/EPEC.

The interaction of pathogenic effectors and host proteins has garnered increased attention (Kim et al., 2010). Apart from the domain architecture of EspF, its interaction with host proteins is also impressive. The challenge now is to identify host proteins that interact with EspF to decipher their effects on cellular physiology and provide molecular clues to EspF pathogenicity. In this review, we emphasize the cellular biological events produced by EspF-host-protein complexes, discuss recent observations of EspF and its binding proteins, describe some new insights into pathogen-host intercommunication, and discuss the molecular mechanisms of hemorrhagic enteritis and diarrhea caused by EHEC/EPEC infection.

\section{DOMAIN ARCHITECTURE OF THE ESPF PROTEIN}

A/E pathogens have a $35.5 \mathrm{~kb}$ LEE (locus of enterocyte effacement) pathogenicity island on their chromosomes (Gaytán et al., 2016). There are many virulence genes on the LEE island, including T3SS and six known effector proteins: Tir, Map, EspF, EspG, EspH, and EspZ (Wong et al., 2011; Gaytán et al., 2016). The espF gene is located on LEE4, the fourth operon of the LEE island. The $\mathrm{N}$-terminal region (residues 1 to 73) of EspF is highly conserved, and secretory signal amino acid residues 1-20 of this region help EspF secrete from the bacteria and transport to host cells (Charpentier and Oswald, 2004). The mitochondrial targeting signal (residues 1-24) and the nucleolar targeting domain (residues 21-74) enable EspF to target the mitochondria and nucleolus of host cells (Holmes et al., 2010). The C-terminal region consists of 3-4 eukaryotic-like proline-rich repeats (PRRs), in which PRR1 contains a $\mathrm{SH} 3$ (src homology 3) binding motif PxxP, an effective Cdc42/Racinteractive binding (CRIB) domain, and a possible actin binding domain (Holmes et al., 2010) (Figure 1A). The highly conserved RxAPxxP motif at residues $75-81$ can bind specifically with the $\mathrm{SH} 3$ binding domain of the host cell SNX9 protein, and the EspF protein can also bind the N-WASP protein through the xHLAAYExSKxxxx sequence located at residues 102-115 (Figure 1B).

The espF gene sequences of EPEC and EHEC are up to $87 \%$ similar (Ugalde-Silva et al., 2016), while CR espF only has $67 \%$ similarity to that of EPEC and 65\% to that of EHEC (Deng et al., 2001). CR has an espF gene of 906 bp with 5 PRRs and a corresponding 301 amino acid residues. EPEC has an espF gene of $621 \mathrm{bp}$, and the EspF protein has 206 amino acids with 3 PRRs, while the length of the EHEC espF gene is 747 bp with a corresponding amino acid size of 248 and 4 PRRs. Comparative sequence analysis shows that the EHEC EspF protein has 42 aa more than EPEC with 19 aa substitutions, while CR EspF protein has more than 50 aa variations from EHEC EspF (Figure 1A). The differences in EHEC and EPEC aa sequences are mainly concentrated in PRR1 and PRR2. These discrepancies lead to some differences in pathogenicity, such as in the reduction of epithelial resistance (Viswanathan et al., 2004b). Whole-genome sequencing of the CR virulent strain ICC168 has indicated that it shares a common host infection strategy with EHEC and EPEC (Petty et al., 2009), which makes CR an ideal model to study EPEC and EHEC infection in vivo.

EspF was first discovered in EPEC by McNamara and Donnenberg (1998). Since then, researchers have gradually increased our knowledge of EspF. Recently, Dean and Kenny have found that EPEC EspF can induce multinucleation and cell-cell internalization of intestinal epithelial cells accompanied by cell fusion events, which depend on its C-terminal proline repeat sequence (Dean and Kenny, 2013). This result reveals a new function of the C-terminal domain of the EspF protein. The domain architecture of EspF determines some of its interacting proteins, such as SNX9 and N-WASP, which determines its fate and plays an important role in its pathogenicity. It also important to determinewhether the differences in PRR repeats are just a result of DNA replication or if they have a host-specific role. At present, the structure of EspF protein is still under investigation, and we believe that there are more mysteries in EspF's structure that are worth exploring.

\section{TARGETING OF HOST CELLS}

Currently, 10 proteins have been screened and verified to interact with EspF in host cells (Table 1), but how their interactions play a role in infection is poorly understood. We will analyze how EspF protein behaves as a versatile effector by interacting with host proteins, and discuss the potential effects in the pathogenesis of EHEC and EPEC.

\section{Targeting Mitochondria}

The targeting of EspF protein to host cells is mainly determined by its N-terminal domain. EPEC EspF targets mitochondria 


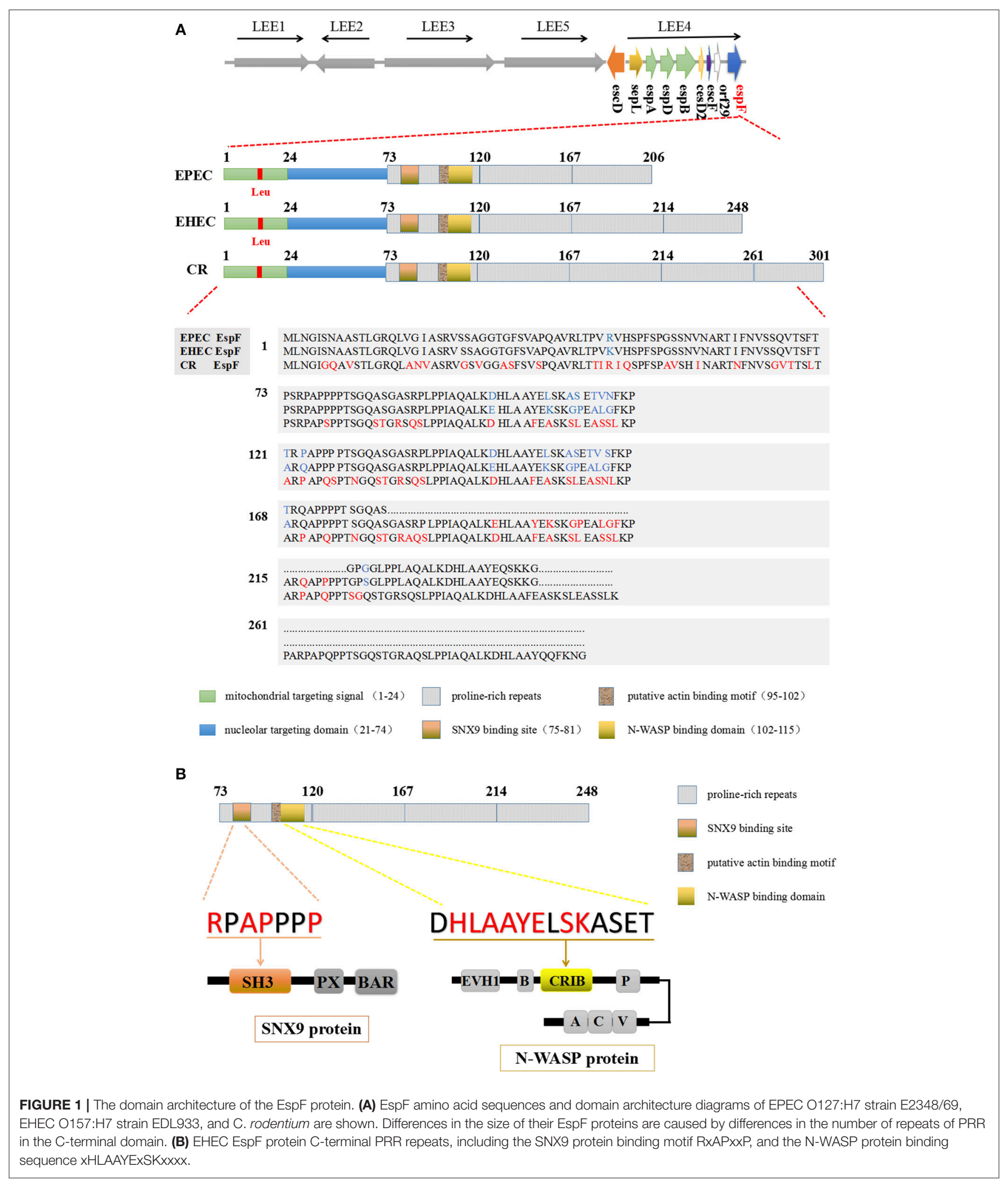

through its mitochondrial targeting domain, and accelerates the targeting through the mitochondrial membrane protein Tom20, which it may interact with (Muto et al., 2001; Nagai et al.,
2005). This results in the destruction of mitochondrial membrane potential (MMP), the release of cytochrome $c$ into the cytoplasm, the cleavage of caspases 9 and 3, and the initiation of the 
TABLE 1 | EspF host binding partners and their biological functions.

\begin{tabular}{|c|c|c|c|}
\hline $\begin{array}{l}\text { Binding } \\
\text { partner }\end{array}$ & Notes & The function of the protein itself a & Biological effects of binding to EspF \\
\hline SNX9 & $\begin{array}{l}\text { Belongs to } \\
\text { sorting nexin } \\
\text { family }\end{array}$ & $\begin{array}{l}\text { 1. Interacts with adaptor protein 2, dynamin, tyrosine kinase } \\
\text { non-receptor } 2 \text {, Wiskott-Aldrich syndrome-like, and Arp3. } \\
\text { 2. Participates in intracellular trafficking, including endocytosis, } \\
\text { macropinocytosis, and F-actin nucleation. }\end{array}$ & $\begin{array}{l}\text { 1. Influences the regulation of clathrin-mediated endocytosis. } \\
\text { 2. Mediates membrane remodeling. } \\
\text { 3. Enhances the invasion of intestinal epithelial cells by EPEC. }\end{array}$ \\
\hline N-WASP & $\begin{array}{l}\text { Belongs to the } \\
\text { Wiskott-Aldrich } \\
\text { syndrome (WAS) } \\
\text { family }\end{array}$ & $\begin{array}{l}\text { 11. Involved in transduction of signals from receptors on the cell } \\
\text { surface to the actin cytoskeleton. } \\
\text { 2. Associate with the small GTPase, Cdc } 42 \text {. } \\
\text { 3. Regulates actin filament reorganization via its interaction with } \\
\text { the Arp2/3 complex and mediate the formation of actin } \\
\text { pedestals upon infection by pathogenic bacteria. }\end{array}$ & $\begin{array}{l}\text { 1. Mediates actin polymerization. } \\
\text { 2. Induces Arp2/3-dependent actin assembly. } \\
\text { 3.Mediates membrane remodeling. }\end{array}$ \\
\hline Actin & $\begin{array}{l}\text { Belongs to the } \\
\text { actin family of } \\
\text { proteins }\end{array}$ & $\begin{array}{l}\text { 1. Plays a role in cell motility, structure and integrity. } \\
\text { 2. One of the most highly-conserved proteins known. } \\
\text { 3. Is found in two main states: G-actin is the globular monomeric } \\
\text { form, whereas F-actin forms helical polymers. Both G- and F-actin } \\
\text { are intrinsically flexible structures. }\end{array}$ & $\begin{array}{l}\text { 1. Promotes pedestals maturation. } \\
\text { 2. Disrupt paracellular permeability. } \\
\text { 3. Mediated endocytosis of TJ proteins and may disrupt TJs. }\end{array}$ \\
\hline Arp2/3 & $\begin{array}{l}\text { Actin related } \\
\text { protein } 2 / 3\end{array}$ & $\begin{array}{l}\text { The Arp2/3 protein complex has been implicated in the control of } \\
\text { actin polymerization in cells and has been conserved throughout } \\
\text { evolution. }\end{array}$ & $\begin{array}{l}\text { 1. Cause the polymerization-depolymerization cycles of actin. } \\
\text { 2. Promotes pedestals maturation. } \\
\text { 3. Disrupts paracellular permeability. } \\
\text { 4. Mediates endocytosis of TJ proteins and may disrupt TJs. }\end{array}$ \\
\hline ZO-1 & $\begin{array}{l}\text { Zonula } \\
\text { occludens-1, act } \\
\text { as a tight } \\
\text { junction adaptor } \\
\text { protein }\end{array}$ & $\begin{array}{l}\text { 1. Act as a scaffold protein and regulate adherens junctions. } \\
\text { 2. Interact with transmembrane proteins, cytosolic proteins, and } \\
\text { F-actin, which are required for tight junction function. } \\
\text { 3. Alternative splicing results in multiple transcript variants } \\
\text { encoding different isoforms. }\end{array}$ & $\begin{array}{l}\text { 1. Causes polymerization-depolymerization cycles of actin. } \\
\text { 2. Promotes pedestals maturation. } \\
\text { 3. Disrupts paracellular permeability. } \\
\text { 4. Mediates endocytosis of TJ proteins and may disrupt TJs. }\end{array}$ \\
\hline $\begin{array}{l}\text { Cytokeratin } \\
18\end{array}$ & $\begin{array}{l}\text { Member of the } \\
\text { intermediate } \\
\text { filament gene } \\
\text { family }\end{array}$ & $\begin{array}{l}\text { 1. Play a role in filament reorganization. } \\
\text { 2. Cadherin binding involved in cell-cell adhesion }\end{array}$ & $\begin{array}{l}\text { 1. Changes the architecture of the intermediate filament network. } \\
\text { 2. May disrupt TJs. }\end{array}$ \\
\hline Abcf2 & $\begin{array}{l}\text { Belongs to the } \\
\text { ABC protein } \\
\text { superfamily }\end{array}$ & $\begin{array}{l}\text { 1. Be characterized as the product of an iron-inhibited } \\
\text { transcribed gene. } \\
\text { 2. Act as a cytoprotective, anti-apoptotic factor. }\end{array}$ & Facilitates host cell death. \\
\hline Anxa6 & $\begin{array}{l}\text { Belongs to a } \\
\text { family of calcium } \\
\text { dependent } \\
\text { membrane and } \\
\text { phospholipid } \\
\text { binding proteins }\end{array}$ & $\begin{array}{l}\text { 1. Annexin VI has been implicated in mediating the endosome } \\
\text { aggregation and vesicle fusion in secreting epithelia during } \\
\text { exocytosis. } \\
\text { 2. Alternatively spliced transcript variants have been described. } \\
\text { 3. May associate with } \mathrm{CD} 21 \text {. } \\
\text { 4. May regulate the release of } \mathrm{Ca}(2+) \text { from intracellular stores. }\end{array}$ & $\begin{array}{l}\text { 1. May rearrange cytoskeleton. } \\
\text { 2. May inhibit phagocytosis. } \\
\text { 3. May downregulate EGFR. }\end{array}$ \\
\hline
\end{tabular}

a The function of the protein itself comes from UniProtKB/Swiss-Prot Function.

mitochondrial apoptosis pathway, eventually leading to cell death (Nougayrède and Donnenberg, 2004). The transportation of EspF to mitochondria is crucial in the EHEC/EPEC infection process. Nagai et al. have replaced the leucine at position 16 with glutamate, and this alteration completely abolishes the mitochondrial targeting of EspF and consequently affects the mitochondrial apoptosis pathway; this observation confirms that the 16th Leu plays a decisive role in the mitochondrial targeting of EspF (Nagai et al., 2005).

\section{Targeting the Nucleolus}

EspF was the first bacterial protein recognized to target the nucleolus. Paul et al. found that EPEC utilize mitochondria to control the timing of and extent to which EspF targets the nucleolus. In the early stage of infection, EspF accumulates in mitochondria and causes the loss of MMP, which determines when EspF is available for targeting the nucleolus. In the later stage of infection, EspF targets the nucleolus through its $\mathrm{N}$ terminal domain, leading to the relocalization of nucleolin to 
the cytoplasm and a reduction in the level of the ribosomal protein RPL9 (Dean et al., 2010). This nucleolar targeting of EspF is strictly controlled by EPEC's modulation of host mitochondria (Dean et al., 2010), thus we speculate that the process of targeting mitochondria must occur before targeting the nucleolus. Although the role of EspF targeting the nucleolus in EPEC disease is unclear, the revelation that bacterial pathogens use host organelles for spatiotemporal control over its effector proteins provides us with new insights into bacterial effector targeting.

A proteomic analysis has shown that the amount of many ribosomal proteins decreases after EPEC infection (Hardwidge et al., 2004), and pre-rRNA processing is blocked in host cells expressing EspF, which requires the EspF nucleolar-targeting domain (Dean et al., 2010). EPEC may destroy the ribosome biosynthesis process by adjusting ribosomal protein levels after a period of infection. We hypothesize that there exists some cooperation between EspF and ribosomal proteins, and that EspF may attenuate ribosome processing by targeting the endoplasmic reticulum. Although its role in disease is obscure, it may help pathogens escape host cell defense responses by reducing the synthesis of ribosomal proteins in long-term infections.

\section{PROMOTION OF BACTERIAL COLONIZATION}

The specific interaction of EPEC EspF and SNX9 protein in intestinal epithelial cells was first discovered by Marche et al. using immunoprecipitation and confocal microscopy in 2006; the proteins colocalize in HeLa cells (Marchès et al., 2006). Subsequently, Alto et al. confirmed that EPEC EspF not only interacts with SNX9 protein but also with neuronal WiskottAldrich syndrome protein (N-WASP) (Alto et al., 2007).

The SNX9 protein contains three conserved regions: SH3, PX, and BAR (Figure 1B). SH3 consists of 50-60 aa and is responsible for the recognition of cellular signal proteins that are rich in proline-producing PxxP modules (such as the Src and Abl tyrosine kinase protein families), and for mediating protein interactions (Aitio et al., 2010; Bendris and Schmid, 2017). The SNX9 protein is an intracellular membrane regulator that can cause the formation of membranous tubules, induce cell membrane remodeling, and promote bacterial invasion (Weflen et al., 2010). The SNX9 and SNX18 proteins form a heterodimer in the membrane that activates the GTPase domain of dynamin and interacts with N-WASP (Park et al., 2010). EPEC EspF forms a protein complex with SNX9 and N-WASP and actives an endogenous SNX9/N-WASP signaling pathways to regulate diverse eukaryotic trafficking events (Alto et al., 2007; Weflen et al., 2009; Garber et al., 2018).

The C-terminal BAR domain of SNX9 is a membraneinteracting promoter that can sense changes in membrane curvature and induce membrane tubularization (Chen et al., 2013). SNX9 targets clathrin-coated pits (CCPs) that are rich in bis- and trisphosphorylated phosphatidylinositol molecules; this targeting specificity allows the regulation of SNX9 and its binding proteins, which include N-WASP and dynamin, during clathrin-mediated endocytosis (CME) (Shin et al., 2008). SNX9 also binds to clathrin and adaptor protein 2 (AP2) through a motif in the low complexity (LC) domain to further strengthen its localization in CCP (Lundmark and Carlsson, 2002). The combination of specificity and high affinity between EspF and SNX9 remodels the plasma membrane, leading to plasma membrane deformation, and these membrane remodeling events are directly related to N-WASP/Arp2/3mediated actin nucleation (Alto et al., 2007).

EPEC EspF promotes the colonization and invasion of pathogenic bacteria to intestinal epithelial cells by relying on the interaction with SNX9 (Weflen et al., 2010). The activation of N-WASP and SNX9 by EspF may be a pathogenic strategy to mimic the SNX9/N-WASP signaling complex in the natural host. We propose a model in which EspF utilizes multiple steps to promote the colonization and invasion of pathogens: recruitment to the plasma membrane, membrane deformation, actin polymerization, and pedestal formation (Figure 2).

First, after EPEC/EHEC contacts the host, the translocated intimin receptor (Tir) is secreted into the cytoplasm of epithelial cells (Campellone, 2010), then Tir inserts into the plasma membrane and interacts with intimin on the surface of EPEC/EHEC, providing a foothold for further adhesion of pathogenic bacteria onto epithelial cells (Kenny et al., 1997).

Second, Tir recruits clathrin and causes it to accumulate at the point of pathogen attachment. EPEC/EHEC adhesion leads to a series of changes in the plasma membrane, such as PIP accumulation, aggregation of phosphorylated tyrosine membrane receptor Tir, and even the formation of a curved membrane surface (Touz et al., 2004; Sason et al., 2009; Weflen et al., 2010). These provide a favorable environment for the recruitment of SNX9 proteins. Under normal circumstances, SNX9 will recruit its partner dynamin to these membrane areas. After recruitment, EspF interacts with the $\mathrm{SH} 3$ domain of SNX9 protein, and this interaction requires at least two SNX9 binding sites (Weflen et al., 2010). The 3-4 binding sites in EspF may facilitate the binding of EspF to the SNX9 SH3 domain in competition with dynamin, and further consolidate its interaction with SNX9. Multiple SNX9 binding domains allow EspF to bind 3-4 molecules of SNX9, subsequently inducing SNX9 oligomerization and increasing membrane deformation activity.

Third, membrane remodeling events are associated with $\mathrm{N}$ WASP/Arp2/3-mediated actin nucleation. SNX9 combines with $\mathrm{N}$-WASP through its SH3 domain, thus stimulating N-WASP to trigger Arp2/3-dependent polymerization of branched-chain actin filaments (Alto et al., 2007). EspF has 3-4 N-WASP binding sites, allowing it to recruit and interact with N-WASP to initiate actin fiber branching and assembly through the Arp2/3 complex (Alto et al., 2007; Weflen et al., 2010). Thus, we propose that EspF activates SNX9 and N-WASP through spatial coordination and regulates its peripheral proteins to cause membrane deformation, actin polymerization, and pedestal formation, thereby facilitating the colonization of pathogenic bacteria.

Although the formation of pedestals is of significance for the colonization of pathogens, its specific functional mechanism 


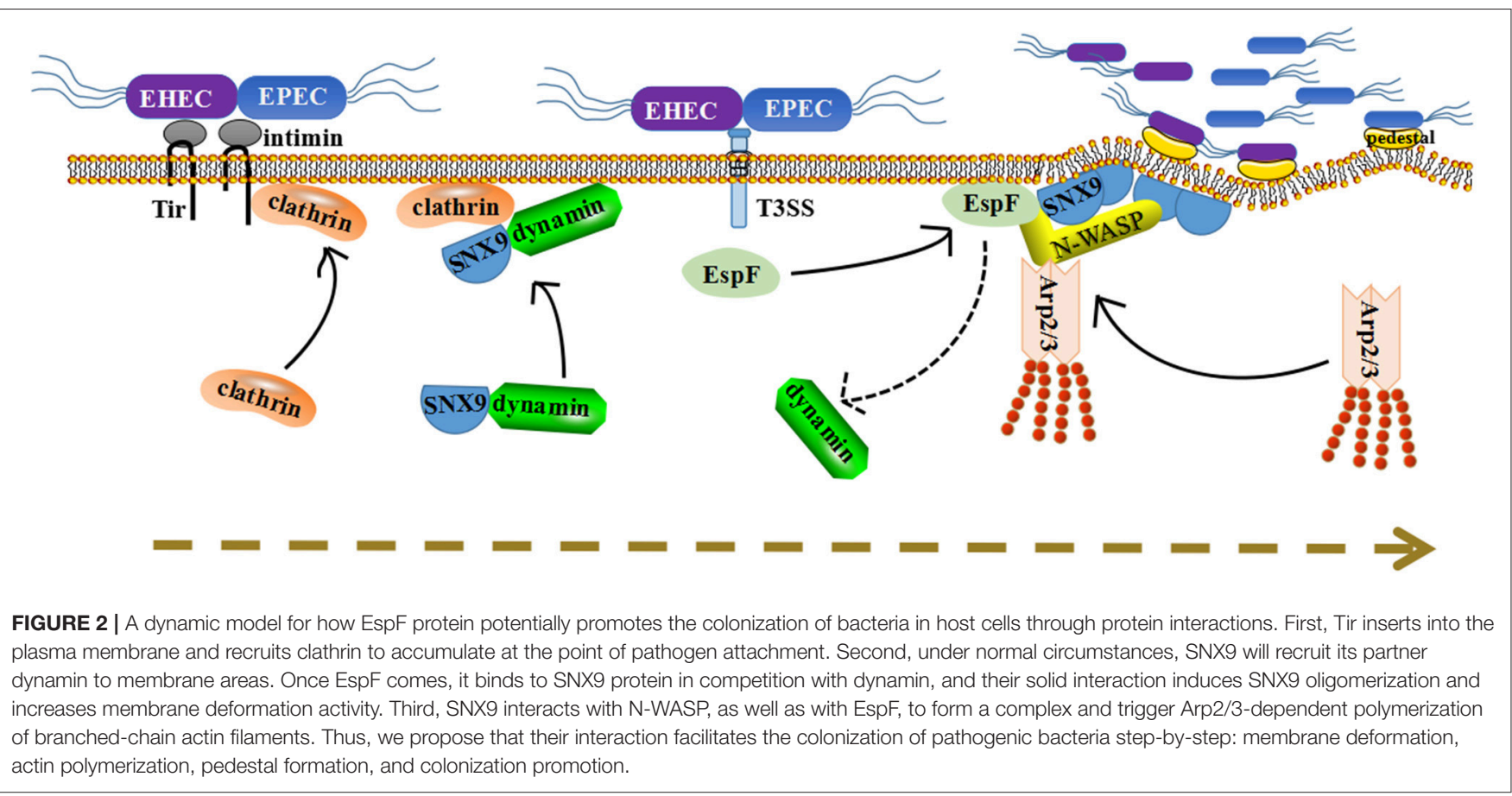

is still undetermined. The adhesion of pathogenic bacteria to epithelial cells may make the bacteria more resistant to fluidmediated separation during diarrhea. In any case, EspF clearly forms a protein complex with SNX9 and N-WASP, and this plays a pivotal role in promoting bacterial colonization.

\section{DESTRUCTION OF TIGHT JUNCTIONS}

One of the characteristics of EPEC/EHEC infection is increased permeability of solutes through intestinal epithelial cells (Viswanathan et al., 2004b). Intestinal epithelial cells adhere to adjacent cells through an adhesive complex that includes tight junctions (TJs), adherens junctions, and desmosomes (Singh et al., 2018). Upon infection, the distribution of tight junction proteins is changed and the tight junction structure and barrier function are disrupted. EPEC EspF plays a pivotal role in the destruction of TJs and the augmentation of membrane permeability, resulting in the loss of transepithelial electrical resistance and the relocation of the tight junctionassociated protein occluding (Zhang et al., 2010), but the specific mechanism has not been defined. We speculate that EspF protein may destroy TJs gradually by recruiting a series of proteins such as actin, profilin, N-WASP, ZO-1, etc., and combining different proteins in different biological processes.

Tight junctions are complex structures that are key in establishing polarity and barrier functions, and they are located in the most apical region of epithelial and endothelial cell junction complexes (Van Itallie and Anderson, 2014). Tight junctions, like a fence, limit the diffusion of lipids and intimal proteins between the apical and basolateral membranes to establish polarity and barrier function (Turner et al., 2014). In addition, they act as physical barriers that regulate the paracellular transportation of water, ions, solutes, and immune cells (Pawłowska and Sobieszczanska, 2017). The transmembrane proteins occludin, $\mathrm{ZO}-1$, and claudin are well-known tight junction functional proteins (Runkle and $\mathrm{Mu}, 2013$ ). Occludin and claudins directly regulate the permeability of uncharged and charged molecules, respectively. ZO-1 serves as a link between the cytoskeleton and TJs. ZO-1, claudin, and occludin interact with actin via different domains, and their interactions contribute to the molecular linkage between the cytoskeleton and tight junction complexes (Van Itallie et al., 2009; Günzel and Fromm, 2012; Runkle and Mu, 2013; Krug et al., 2014; Zihni et al., 2016).

EspF of rabbit enteropathogenic E. coli (E22) interacts with actin and profilin, and this interaction takes place throughout the infection process (Peralta-Ramírez et al., 2008). Profilin is a small-molecule protein that binds to actin monomers and then delivers them to the fast-growing end of actin filaments (Pantaloni and Carlier, 1993; Witke, 2004). EspF may be involved in the regulation of actin polymerization as a nucleation promoting factor through direct interaction with actin or indirect interactions between profilin and actin.

EspF of E22 interacts with N-WASP, Arp2/3, ZO-1, and ZO-2 directly or indirectly within $2 \mathrm{~h}$ post-infection (PeraltaRamírez et al., 2008). The cooperation of EspF with these proteins is not a collection of independent events but a series of consecutive related events. EspF binds to N-WASP and Arp2/3, inducing actin polymerization and pedestal formation. EspF of E22 interacts with actin and immobilizes it, allowing the recruitment of junction proteins into the pedestal, resulting in the redistribution of tight junction proteins, the maturation of the actin-rich pedestals, and the disruption of paracellular permeability (Peralta-Ramírez et al., 2008). EspF of E22 can also bind to ZO-1 and ZO-2 scaffold proteins, sequestering 
actin and profilin, inducing local actin depolymerization, and resulting in the imbalance of polymerization-depolymerization cycles (Peralta-Ramírez et al., 2008). Studies have shown that depolymerization of actin disrupts tight junctions through caveolin-mediated endocytosis of occluding (Shen and Turner, 2005).

During EPEC infection, EspF can also interact with cytokeratin 18 (CK18) and 14-3-35 to form a complex that increases the solubility of CK18 and alters the distribution of intermediate filaments, resulting in the decomposition of the intermediate filament network (Viswanathan et al., 2004a). However, the role of this event in the pathogenicity of EPEC is still undetermined. EPEC has been demonstrated to enhance myosin light chain (MLC) phosphorylation (Yuhan et al., 1997), and EspF may combine with calmodulin through $14-3-3 \zeta$ to activate and phosphorylate MLC, which disturbs the tight junction barrier process.

Recent studies have shown that EPEC EspF depletes junction proteins through transcriptional and post-transcriptional mechanisms and interacts with $\mathrm{ZO}-1$ to regulate tight junction assembly and disassembly, thereby affecting the integrity of the barrier and disrupting tight junctions (Singh et al., 2018). EPEC EspF can also promote the endocytosis of Crumbs3 (Crb3) by binding to SNX9, which disrupts the polarity of intestinal epithelial cells, destroys tight junctions, changes the absorption of ions and solutes by membrane transporters, and promotes EPEC-associated diarrhea (Tapia et al., 2017).

Thus, we propose that EspF may disrupt TJs through a multipronged strategy during EPEC/EHEC infection: it interacts with actin and profilin at the pedestal to immobilize actin, recruits junction proteins to the pedestal, promotes the maturation of the pedestal, and disrupts paracellular permeability. Then tight junction proteins occludin, claudin, and $\mathrm{ZO}-1$ redistribute, resulting in transepithelial resistance loss. EspF then binds to the scaffold proteins $\mathrm{ZO}-1$ and $\mathrm{ZO}-2$, causing actin depolymerization, resulting in an unbalanced state of polymerization-depolymerization, and thus TJ breakdown (Figure 3). Although the specific mechanism of EspF-induced TJ disruption remains mysterious, its interactions with $\mathrm{N}$ -

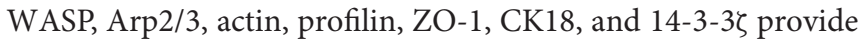
clues.

\section{INHIBITION OF PHAGOCYTOSIS}

The internalization process is detrimental to EHEC/EPEC, and recruiting macrophages are often an effective strategy for host cells to prevent and eliminate infections (Sarantis and Grinstein, 2012). Correspondingly, pathogens also have coping strategies. EspF protein is a highly evolved coping strategy.

There are two steps involved in the internalization process of EHEC/EPEC, the transportation process of $\mathrm{M}$ cells and then the phagocytosis by macrophages (Martinez-Argudo et al., 2007). M cells are specialized epithelial cells that are distinguished from other epithelial cells by their high transport capacity. When pathogens invade, $M$ cells transport them to downstream immune cells, such as macrophages, to clear them (Brayden et al., 2005; Mabbott et al., 2013).

Although $\mathrm{M}$ cells have high transport capacity, studies have shown that their capacity to transport EPEC is lower than that of Salmonella. The deletion of T3SS or EspF protein significantly increases the translocation rate, and a phosphatidyl inositol 3kinase (PI3K) inhibitor can decrease the translocation rate of EPEC strains with loss of T3SS function (Martinez-Argudo et al., 2007).

EPEC mediates antiphagocytosis by inhibiting the PI3K pathway, and the EspF protein inhibits the phagocytosis of EPEC by J774.A1 macrophages via a PI3K-dependent pathway, which depends on its $\mathrm{N}$-terminal domain, playing a crucial part in the anti-phagocytosis process (Celli et al., 2001; Quitard et al., 2006).

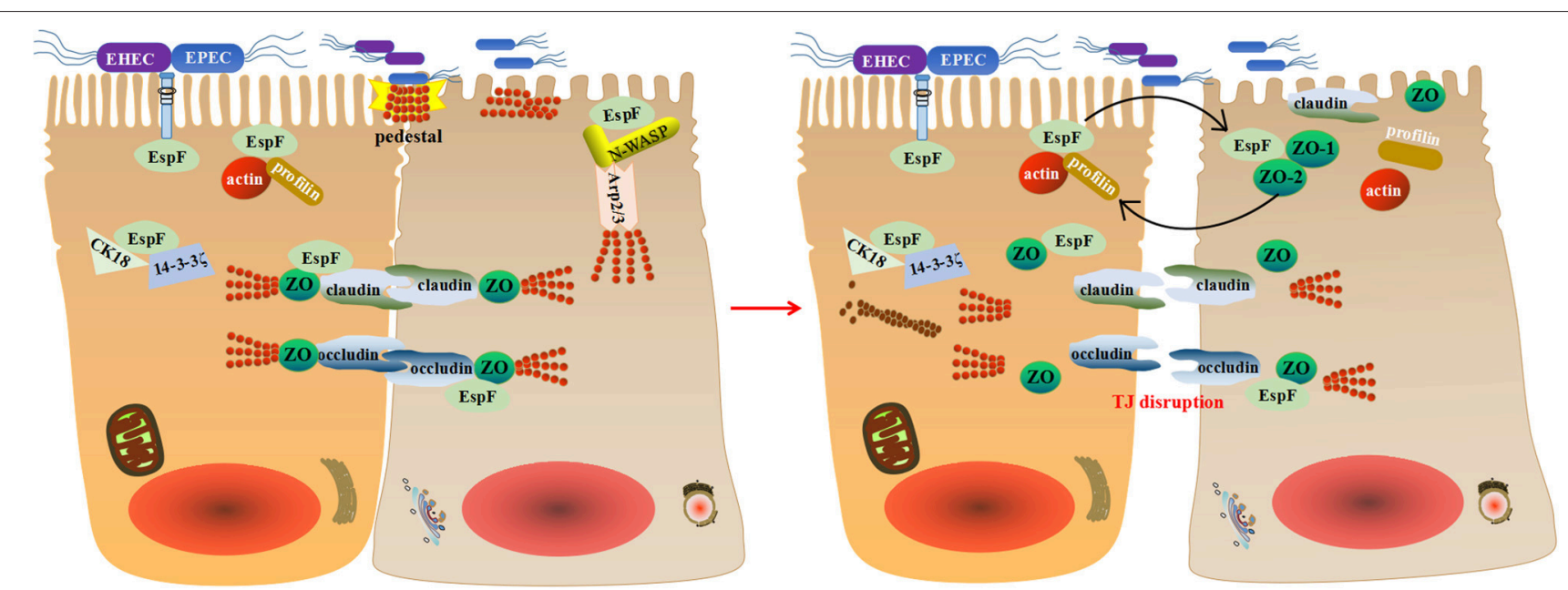

FIGURE 3 | A schematic model for how EspF potentially disrupts tight junctions. EspF interacts with CK18 and $14-3-3 \zeta$ to redistribute intermediate filaments and combines with N-WASP, Arp2/3, actin, profilin, and ZO-1 to recruit junctional proteins to the pedestal. This results in the redistribution of tight junction proteins, depolymerization of actin, and interruption of tight junctions. 
The role of EspF in regulating EPEC transportation by $\mathrm{M}$ cells appears to be similar to its antiphagocytic effect in macrophages.

Poirier et al. confirmed that EHEC O157:H7 survives after infecting human macrophages; although the macrophages try to clear the pathogens, after $24 \mathrm{~h}$ of infection, some infected macrophages hold larger numbers of bacteria than at early infection points, indicating that the bacteria not only survive but replicate inside macrophages (Poirier et al., 2008). However, our understanding of the anti-phagocytotic mechanisms of EHEC is very poor.

Recently, we screened and verified that Annexin A6 (Anxa6) interacts with EHEC O157:H7 EspF using Bimolecular Fluorescence Complementation (BiFC) technology for the first time (Hua et al., 2018). Anxa6 belongs to a highly conserved protein family characterized by calcium-dependent binding to phospholipids. As a multifunctional scaffold protein, Anxa6 is involved in many biological processes including cell proliferation, survival, differentiation, and inflammation (Grewal et al., 2017). It can interact with actin, leading to the formation of membrane-cytoskeletal complexes, which may affect actin dynamics by recruiting signaling proteins and forming complex protein interaction networks, thereby remodeling the actin cytoskeleton (Hayes et al., 2004; Mishra et al., 2011; Grewal et al., 2017). The significance of actin for phagocytosis has been welldocumented (Castellano et al., 2001; Smythe and Ayscough, 2006; Carlsson, 2017), and the actin-binding molecule profilin is also recruited to $\mathrm{FC} \gamma \mathrm{R}$-mediated phagocytic cups (Coppolino et al., 2001).

The actin cytoskeleton plays a critical role in regulating the epidermal growth factor receptor (EGFR) cycle and controlling endocytosis and degradation of EGFR (Da Costa et al., 2003;
Smythe and Ayscough, 2006). Anxa6 can interact with the actin cytoskeleton and may lead endocytic vesicles to multivesicular bodies. Anxa6 can also bind to p120GAP and PKC $\alpha$, thus negatively controlling the EGFR/Ras pathway (Grewal and Enrich, 2009).

EHEC/EPEC infection can regulate the host cytoskeleton by activating $\mathrm{PKC} \alpha$ and recruiting $\mathrm{PKC}$ to form adhesion pedestals through functionally intact lipid rafts (Crane and Oh, 1997; Shen-Tu et al., 2014), but the mechanism is undetermined. The activation of PKC is controlled by the PI-3 (phosphatidyl inositol 3)/AKT signaling pathway, and EPEC relies on this pathway to escape the phagocytosis of host cell macrophages (Celli et al., 2001; Shen-Tu et al., 2014). EPEC participates in the activation of EGFR and causes the phosphorylation of EGFR, which promotes host cell survival in early infection, but EspF accelerates the loss of EGFR in late infection leading to a dramatic increase in host cell death (Roxas et al., 2007, 2014).

The detection of Anxa6 protein bound to EspF may provide us with a new mechanism of EspF-mediated anti-phagocytosis: EspF forms a complex with Anxa6 and actin after EPEC/EHEC infects host cells, which regulates the rearrangement of the actin cytoskeleton; reorganization of the cytoskeleton modulates the PI-3/AKT pathway, triggers the activation of $\mathrm{PKC} \alpha$ and the phosphorylation of EGFR, and induces the down-regulation of EGFR. As the complex activates the PI-3/AKT signaling pathway, it restricts phagocytosis and assists in the survival of pathogenic bacteria in macrophages (Figure 4).

We suspect that Anxa6 may be an essential bridge protein for EspF to develop anti-phagocytosis and down-regulate cellular EGFR levels, and we are conducting further research to test this.

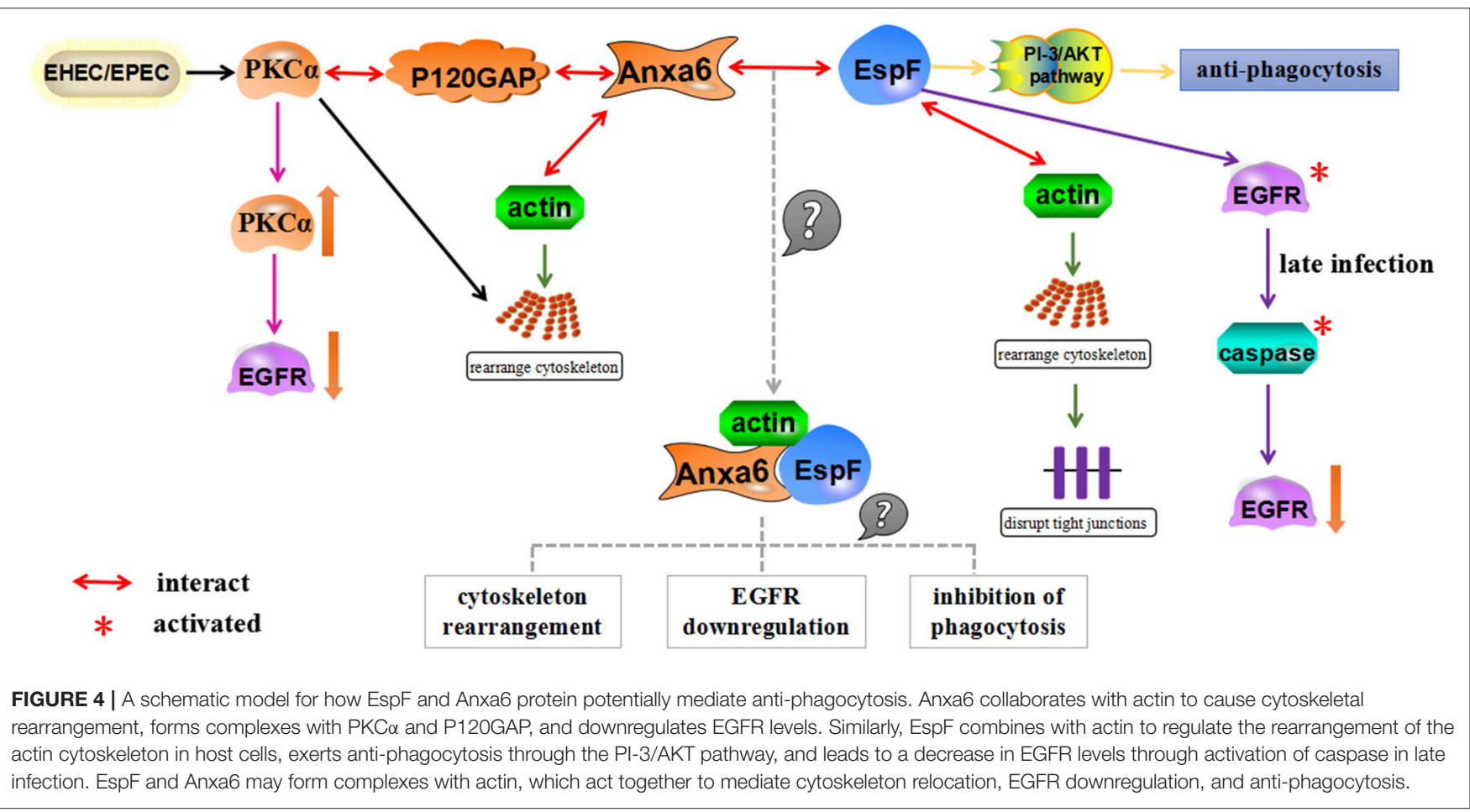




\section{REGULATION OF APOPTOSIS}

During infection of intestinal epithelial cells, the surface properties of EPEC/EHEC induce exogenous apoptotic pathways (Abul-Milh et al., 2001), whereas T3SS effectors such as EspF, Map, and cycle inhibitory factor (Cif) trigger intrinsic apoptotic pathways (Wong et al., 2011).

By destroying the mitochondrial membrane potential, EspF initiates the intrinsic apoptotic pathway, leading to the release of cytochrome $c$, the cleavage of caspases 3 and 9, and eventually cell apoptosis (Nougayrède and Donnenberg, 2004). Our previous research confirmed that the N-terminal region of the EHEC O157:H7 EspF protein causes cell apoptosis (Zhao et al., 2013), and an N-terminal domain-deleted strain reduces the mitochondrial binding affinity of EHEC (Wang et al., 2017).

Up to now, only one EspF-interacting protein, Abcf2, has been shown to be involved in apoptosis (Nougayrède et al., 2007). Abcf2 belongs to the ATP-binding cassette (ABC) transporter superfamily and is a cytoprotective anti-apoptotic factor (AndoAkatsuka et al., 2012; Bao et al., 2017). After infection of EPEC, the host cell Abcf2 protein level is decreased, and the levels of caspase 9 and caspase 3 in Abcf2 gene-silenced cells are reduced, which depend on EspF, indicating that EspF binds to Abcf2 and inhibits its anti-apoptotic effect, thereby inducing or promoting cell apoptosis (Nougayrède et al., 2007). This interesting work highlights the usefulness of identifying interacting proteins in eukaryotic cell biology, because it suggests that the relatively unknown Abcf 2 protein is an anti-apoptotic factor.

Although apoptotic cells issue "find-me" and "eat-me" signals (Davidovich et al., 2014), in the early stages of EHEC/EPEC infection, some inflammatory factor signaling pathways may be triggered, such as NF-кB (Pallett et al., 2014; Yen et al., 2016). EHEC/EPEC applies some mechanism to restrain the early inflammatory response to obtain a longer survival period before the host's overall immune response is induced (Sharma et al., 2006; Ruchaud-Sparagano et al., 2007; Nobe et al., 2009); for example, EPEC can deliver effector Nlec to suppress innate immune responses by inhibiting NF- $\kappa \mathrm{B}$ and MAPK activation (Pearson et al., 2011; Sham et al., 2011). In 2013, Professor Donnenberg of the University of Maryland proposed a hypothesis that $\mathrm{A} / \mathrm{E} E$. coli chronic infection can promote the occurrence of human rectal cancer (Maddocks et al., 2013). A/E E coli infects intestinal epithelial cells and injects virulence proteins that causes DNA damage in the host cells, which increases cancer risk along with the Toll-like receptor signaling pathway, the NF-кB pathway, and other cellular inflammatory pathways (Vogelmann and Amieva, 2007; Maddocks et al., 2009; Kipanyula et al., 2013). Further, EspF decreases host cell DNA mismatch repair (MMR) levels, which can then lead to mutations in the Apc gene (Maddocks et al., 2013). Destruction of the MMR system leads to an increase in the mutation frequency of tumor suppressor genes $A p c$ and $p 53$, which are considered to

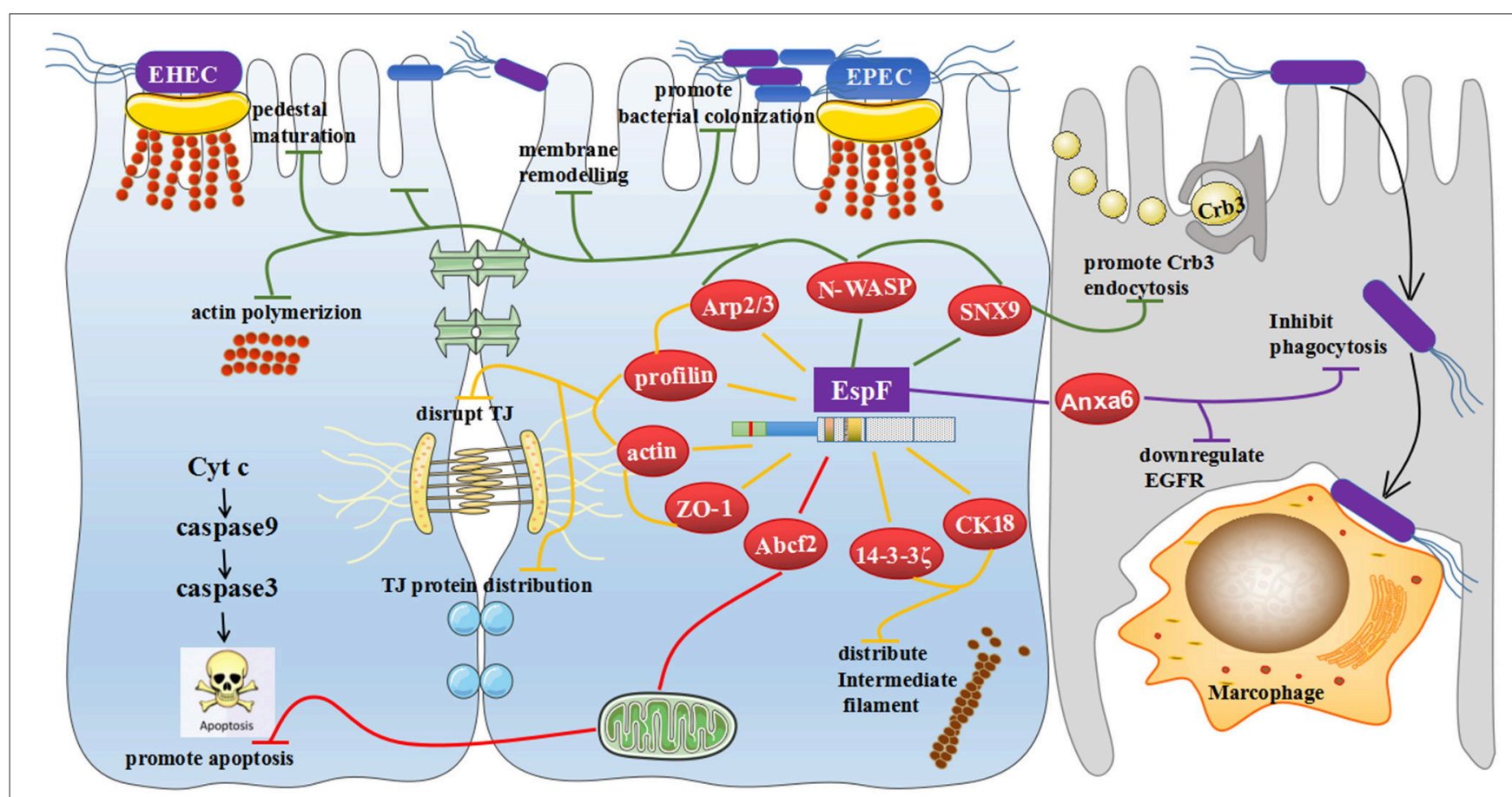

FIGURE 5 | General view of the biological effects mediated by EspF binding to host proteins. EspF interacts with SNX9 to promote endocytosis of the Crb3 protein; combines with SNX9, N-WASP, and Arp2/3 proteins to maturate pedestals; regulates actin polymerization to induce remodeling of cell membranes and potentially promote colonization of pathogenic bacteria; cooperates with Arp2/3, profilin, actin, and ZO-1 to redistribute actin and potentially disrupt the TJs; interacts with 14-3-3 $\zeta$ and CK18 to redistribute intermediate filaments, which may also promote the destruction of TJs; interacts with Abcf2, which may mediate apoptosis through the mitochondrial pathway; and interacts with Anxa6, which may downregulate EGFR levels and inhibit phagocytosis. 
be the most mutagenic genes in colorectal cancer (Smith et al., 2002; Maddocks et al., 2013). This discovery directly confirmed Donnenberg's hypothesis. However, whether all A/E bacterial chronic infections can lead to the occurrence of colorectal cancer, and the specific mechanism, remains to be further investigated.

Apoptosis is a multifactor-mediated event. Increased bacterial colonization, disruption of tight junctions, and inhibition of phagocytosis initiated by EspF binding to host proteins may indirectly lead to eventual cell apoptosis. Apoptosis is also the beginning of the body's immune response, and the process from apoptosis to the generation of inflammation is complicated. We believe that EspF has some other interaction partners that, in addition to co-promoting apoptosis, may also trigger cell inflammatory signaling pathways, leading to cell death. This is worthy of further study.

\section{CONCLUSIONS}

The human body has a variety of innate defense mechanisms to resist the invasion of microorganisms. Host proteins play a decisive role in the immune response, phagocytosis, prevention of adhesion and colonization, and other processes. Nevertheless, many pathogens are equipped with highly evolved infectious strategies, for example secreting "smart" effectors like EspF, which can not only inject into the host cell, but also interact with some host proteins and take advantage of their function to mediate virulence, promote bacterial survival, and destroy host cells.

This review has focused on the clever cooperation between EspF and host proteins: it interacts with SNX9 and promotes endocytosis of Crb3 protein; combines with SNX9, N-WASP, and Arp $2 / 3$ proteins to promote pedestal maturation, regulate actin polymerization, induce cell membrane remodeling, and potentially further the colonization of pathogenic bacteria; cooperates with Arp2/3, profilin, actin, and ZO- 1 to cause actin redistribution and potentially disrupt TJs; interacts with 14-3$3 \zeta$ and CK18 to redistribute intermediate filaments and may also promote tight junction destruction; binds to Abcf2 and facilitates host cell apoptosis; and interacts with Anxa6, which may downregulate EGFR levels and mediate anti-phagocytosis (Figure 5).

EHEC and EPEC infections are characterized by the rapid onset of diarrhea (Viswanathan et al., 2009). EspF's role in causing

\section{REFERENCES}

Abul-Milh, M., Wu, Y., Lau, B., Lingwood, C. A., and Barnett, F. (2001). Induction of epithelial cell death including apoptosis by enteropathogenic Escherichia coli expressing bundle-forming pili. Infect. Immun. 69, 7356-7364. doi: 10.1128/IAI.69.12.7356-7364.2001

Aitio, O., Hellman, M., Kazlauskas, A., Vingadassalom, D. F., Leong, J. M., Saksela, K., et al. (2010). Recognition of tandem PxxP motifs as a unique Src homology 3-binding mode triggers pathogen-driven actin assembly. Proc. Natl. Acad. Sci. U.S.A. 107, 21743-21748. doi: 10.1073/pnas.1010243107

Alto, N. M., Weflen, A. W., Rardin, M. J., Yarar, D., Lazar, C. S., Tonikian, R., et al. (2007). The type III effector EspF coordinates membrane trafficking by diarrhea is the ability to disrupt TJs, but the precise mechanism of EspF's binding to host proteins to cause diarrhea has not been defined. In our previous research, we screened AQP7P2, a type of water channel protein that interacts with EspF (Hua et al., 2018). Their interaction may induce diarrhea by changing the activity of water molecule transport. EspF may also mediate the development of diarrhea by interacting with different host proteins. The interaction of EspF with Abcf2 protein results in apoptosis, which may be associated with inflammation caused by EPEC, but this has not been confirmed.

Although the interaction between $\mathrm{EspF}$ and host proteins has been widely investigated, many problems remain. Since most of the data related to EspF are from research on EPEC rather than EHEC or CR, we may have neglected some other interaction effects, or the interaction effects of different $\mathrm{A} / \mathrm{E}$ pathogens may be different. It is also possible that EspF binds with other virulence proteins to mediate the interaction with host proteins, and these have yet to be studied.

Current research has mainly focused on the interaction between EspF and intestinal epithelial cells. In the future, we need to learn more about the interaction of EspF with immune cells and their role in the pathogenesis of EHEC/EPEC, and explore how EspF influences or participates in innate and adaptive immune responses through interactions with host proteins. The discovery of Anxa6 protein provides us with a new foothold, as we speculate that it may be an key bridge protein for EspF to inhibit phagocytosis and down-regulate EGFR levels. EspF binding to Anxa6 may trigger the PI3/AKT signaling pathway, promote anti-phagocytosis, activate cellular PKC $\alpha$ protein, negatively regulate EGFR signaling, and exacerbate host cell death. These areas are primed for further research.

\section{AUTHOR CONTRIBUTIONS}

$\mathrm{CW}, \mathrm{YH}$ designed and wrote the paper. KY collected the data. Thank all the authors' contribution to the manuscript.

\section{FUNDING}

This work was supported by the National Natural Science Foundation of China (No. 81371765) and the Natural Science Foundation of Guangdong Province (No. 2018B030311063). the spatiotemporal activation of two eukaryotic signaling pathways. J. Cell Biol. 178, 1265-1278. doi: 10.1083/jcb.200705021

Ando-Akatsuka, Y., Shimizu, T., Numata, T., and Okada, Y. (2012). Involvements of the ABC protein ABCF2 and $\alpha$-actinin- 4 in regulation of cell volume and anion channels in human epithelial cells. J. Cell. Physiol. 227, 3498-3510. doi: $10.1002 /$ jcp. 24050

Bao, L., Wu, J., Dodson, M., Rojo De La Vega, E. M., Ning, Y., Zhang, Z., et al. (2017). ABCF2, an Nrf2 target gene, contributes to cisplatin resistance in ovarian cancer cells. Mol. Carcinog. 56, 1543-1553. doi: 10.1002/mc.22615

Bendris, N., and Schmid, S. L. (2017). Endocytosis, metastasis and beyond: multiple facets of SNX9. Trends Cell Biol. 27, 189-200. doi: 10.1016/j.tcb.2016. 11.001 
Brayden, D. J., Jepson, M. A., and Baird, A. W. (2005). Keynote review: intestinal Peyer's patch M cells and oral vaccine targeting. Drug Discov. Today 10, 1145-1157. doi: 10.1016/S1359-6446(05)03536-1

Campellone, K. G. (2010). Cytoskeleton-modulating effectors of enteropathogenic and enterohaemorrhagic Escherichia coli: Tir, EspFU and actin pedestal assembly. FEBS J. 277, 2390-2402. doi: 10.1111/j.1742-4658.2010.07653.x

Carlsson, A. E. (2017). Membrane bending by actin polymerization. Curr. Opin. Cell Biol. 50, 1-7. doi: 10.1016/j.ceb.2017.11.007

Castellano, F., Chavrier, P., and Caron, E. (2001). Actin dynamics during phagocytosis. Semin. Immunol. 13, 347-355. doi: 10.1006/smim.2001.0331

Celli, J., Olivier, M., and Finlay, B. B. (2001). Enteropathogenic Escherichia coli mediates antiphagocytosis through the inhibition of PI 3-kinase-dependent pathways. EMBO J. 20, 1245-1258. doi: 10.1093/emboj/20.6.1245

Charpentier, X., and Oswald, E. (2004). Identification of the secretion and translocation domain of the enteropathogenic and enterohemorrhagic Escherichia coli effector Cif, using TEM-1 beta-lactamase as a new fluorescence-based reporter. J. Bacteriol. 186, 5486-5495. doi: 10.1128/JB.186.16.5486-5495.2004

Chen, Y., Aardema, J., and Corey, S. J. (2013). Biochemical and functional significance of F-BAR domain proteins interaction with WASP/N-WASP. Semin. Cell Dev. Biol. 24, 280-286. doi: 10.1016/j.semcdb.2013.01.005

Collins, J. W., Keeney, K. M., Crepin, V. F., Rathinam, V. A., Fitzgerald, K. A., Finlay, B. B., et al. (2014). Citrobacter rodentium: infection, inflammation and the microbiota. Nat. Rev. Microbiol. 12, 612-623. doi: 10.1038/nrmicro3315

Coppolino, M. G., Krause, M., Hagendorff, P., Monner, D. A., Trimble, W., Grinstein, S., et al. (2001). Evidence for a molecular complex consisting of Fyb/SLAP, SLP-76, Nck, VASP and WASP that links the actin cytoskeleton to Fcgamma receptor signalling during phagocytosis. J. Cell Sci. 114, 4307-4318.

Crane, J. K., McNamara, B. P., and Donnenberg, M. S. (2001). Role of EspF in host cell death induced by enteropathogenic Escherichia coli. Cell. Microbiol. 3, 197-211. doi: 10.1046/j.1462-5822.2001.00103.x

Crane, J. K., and Oh, J. S. (1997). Activation of host cell protein kinase C by enteropathogenic Escherichia coli. Infect. Immun. 65, 3277-3285.

Da Costa, S. R., Okamoto, C. T., and Hamm-Alvarez, S. F. (2003). Actin microfilaments et al.-the many components, effectors and regulators of epithelial cell endocytosis. Adv. Drug Deliv. Rev. 55, 1359-1383. doi: 10.1016/j.addr.2003.07.011

Danika, L., Goosney, J. C., Kenny, B., and Brett Finlay, B. (1999). Enteropathogenic Escherichia coli inhibits phagocytosis. Infect. Immun. 67, 490-495.

Davidovich, P., Kearney, C. J., and Martin, S. J. (2014). Inflammatory outcomes of apoptosis, necrosis and necroptosis. Biol. Chem. 395, 1163-1171. doi: 10.1515/hsz-2014-0164

Dean, P., and Kenny, B. (2013). A bacterial encoded protein induces extreme multinucleation and cell-cell internalization in intestinal cells. Tissue Barriers 1:e22639. doi: 10.4161/tisb.22639

Dean, P., Scott, J. A., Knox, A. A., Quitard, S., Watkins, N. J., and Kenny, B. (2010). The enteropathogenic E. coli effector EspF targets and disrupts the nucleolus by a process regulated by mitochondrial dysfunction. PLoS Pathog. 6:e1000961. doi: 10.1371/journal.ppat.1000961

Deng, W., Li, Y., Vallance, B. A., and Finlay, B. B. (2001). Locus of enterocyte effacement from Citrobacter rodentium: sequence analysis and evidence for horizontal transfer among attaching and effacing pathogens. Infect. Immun. 69, 6323-6335. doi: 10.1128/IAI.69.10.6323-6335.2001

Deng, W., Puente, J. L., Gruenheid, S., Li, Y., Vallance, B. A., Vázquez, A., et al. (2004). Dissecting virulence: systematic and functional analyses of a pathogenicity island. Proc. Natl. Acad. Sci. U.S.A. 101, 3597-3602. doi: 10.1073/pnas.0400326101

Donnenberg, M. S., and Finlay, B. B. (2013). Combating enteropathogenic Escherichia coli (EPEC) infections: the way forward. Trends Microbiol. 21, 317-319. doi: 10.1016/j.tim.2013.05.003

Garber, J. J., Mallick, E. M., Scanlon, K. M., Turner, J. R., Donnenberg, M. S., Leong, J. M., et al. (2018). Attaching-and-effacing pathogens exploit junction regulatory activities of N-WASP and SNX9 to disrupt the intestinal barrier. Cell. Mol. Gastroenterol. Hepatol. 5, 273-288. doi: 10.1016/j.jcmgh.2017.11.015

Gaytán, M. O., Martínez-Santos, V. I., Soto, E., and González-Pedrajo, B. (2016). Type three secretion system in attaching and effacing pathogens. Front. Cell. Infect. Microbiol. 6:129. doi: 10.3389/fcimb.2016.00129
Grewal, T., and Enrich, C. (2009). Annexins - Modulators of EGF receptor signalling and trafficking. Cell. Signal. 21, 847-858. doi: 10.1016/j.cellsig.2009.01.031

Grewal, T., Hoque, M., Conway, J. R. W., Reverter, M., Wahba, M., Beevi, S. S., et al. (2017). Annexin A6-A multifunctional scaffold in cell motility. Cell Adh. Migr. 11, 288-304. doi: 10.1080/19336918.2016.1268318

Günzel, D., and Fromm, M. (2012). Claudins and other tight junction proteins. Compr. Physiol. 2, 1819-1852. doi: 10.1002/cphy.c110045

Hardwidge, P. R., Rodriguez-Escudero, I., Goode, D., Donohoe, S., Eng, J., Goodlett, D. R., et al. (2004). Proteomic analysis of the intestinal epithelial cell response to enteropathogenic Escherichia coli. J. Biol. Chem. 279, 20127-20136. doi: $10.1074 /$ jbc.M401228200

Hartland, E. L., and Richardson, A. R. (2016). Editorial overview: Host-microbe interactions: bacteria: secretion systems, effectors, immunity and metabolism. Curr. Opin. Microbiol. 29, v-vii. doi: 10.1016/j.mib.2015.12.003

Hayes, M. J., Rescher, U., Gerke, V., and Moss, S. E. (2004). Annexin-actin interactions. Traffic 5, 571-576. doi: 10.1111/j.1600-0854.2004.00210.x

Holmes, A., Mühlen, S., Roe, A. J., and Dean, P. (2010). The EspF effector, a bacterial pathogen's swiss army knife. Infect. Immun. 78, 4445-4453. doi: 10.1128/IAI.00635-10

Hua, Y., Ju, J., Wang, X., Zhang, B., Zhao, W., Zhang, Q., et al. (2018). Screening for host proteins interacting with Escherichia coli O157:H7 EspF using bimolecular fluorescence complementation. Future Microbiol. 13, 37-58. doi: 10.2217/fmb-2017-0087

Kenny, B., DeVinney, R., Stein, M., Reinscheid, D. J., Frey, E. A., and Finlay, B. B. (1997). Enteropathogenic E. coli (EPEC) transfers its receptor for intimate adherence into mammalian cells. Cell 91, 511-520.

Kim, M., Ashida, H., Ogawa, M., Yoshikawa, Y., Mimuro, H., and Sasakawa, C. (2010). Bacterial interactions with the host epithelium. Cell Host Microbe 8, 20-35. doi: 10.1016/j.chom.2010.06.006

Kipanyula, M. J., Seke Etet, P. F., Vecchio, L., Farahna, M., Nukenine, E. N., and Nwabo Kamdje, A. H. (2013). Signaling pathways bridging microbial-triggered inflammation and cancer. Cell. Signal. 25, 403-416. doi: 10.1016/j.cellsig.2012.10.014

Krug, S. M., Schulzke, J. D., and Fromm, M. (2014). Tight junction, selective permeability, and related diseases. Semin. Cell Dev. Biol. 36, 166-176. doi: 10.1016/j.semcdb.2014.09.002

Lundmark, R., and Carlsson, S. R. (2002). The beta-appendages of the four adaptor-protein (AP) complexes: structure and binding properties, and identification of sorting nexin 9 as an accessory protein to AP-2. Biochem. J. 362, 597-607. doi: 10.1042/bj3620597

Mabbott, N. A., Donaldson, D. S., Ohno, H., Williams, I. R., and Mahajan, A. (2013). Microfold (M) cells: important immunosurveillance posts in the intestinal epithelium. Mucosal Immunol. 6, 666-677. doi: 10.1038/mi.2013.30

Maddocks, O. D., Scanlon, K. M., and Donnenberg, M. S. (2013). An Escherichia coli effector protein promotes host mutation via depletion of DNA mismatch repair proteins. MBio 4:e00152-e00113. doi: 10.1128/mBio.00152-13

Maddocks, O. D., Short, A. J., Donnenberg, M. S., Bader, S., and Harrison, D. J. (2009). Attaching and effacing Escherichia coli downregulate DNA mismatch repair protein in vitro and are associated with colorectal adenocarcinomas in humans. PLoS ONE 4:e5517. doi: 10.1371/journal.pone.0005517

Marchès, O., Batchelor, M., Shaw, R. K., Patel, A., Cummings, N., Nagai, T., et al. (2006). EspF of enteropathogenic Escherichia coli binds sorting nexin 9. J. Bacteriol. 188, 3110-3115. doi: 10.1128/JB.188.8.3110-3115.2006

Martinez-Argudo, I., Sands, C., and Jepson, M. A. (2007). Translocation of enteropathogenic Escherichia coli across an in vitro $\mathrm{M}$ cell model is regulated by its type III secretion system. Cell. Microbiol. 9, 1538-1546. doi: 10.1111/j.1462-5822.2007.00891.x

McNamara, B. P., and Donnenberg, M. S. (1998). A novel prolinerich protein, EspF, is secreted from enteropathogenic Escherichia coli via the type III export pathway. FEMS Microbiol. Lett. 166, 71-78. doi: 10.1111/j.1574-6968.1998.tb13185.x

Mishra, S., Chander, V., Banerjee, P., Oh, J. G., Lifirsu, E., Park, W. J., et al. (2011). Interaction of annexin A6 with alpha actinin in cardiomyocytes. BMC Cell Biol. 12:7. doi: $10.1186 / 1471-2121-12-7$

Mundy, R., Petrovska, L., Smollett, K., Simpson, N., Wilson, R. K., Yu, J., et al. (2004). Identification of a novel Citrobacter rodentium type III secreted protein, 
EspI, and roles of this and other secreted proteins in infection. Infect. Immun. 72, 2288-2302. doi: 10.1128/IAI.72.4.2288-2302.2004

Muto, T., Obita, T., Abe, Y., Shodai, T., Endo, T., and Kohda, D. (2001). NMR identification of the Tom20 binding segment in mitochondrial presequences11Edited by M. F. Sumers. J. Mol. Biol. 306, 137-143. doi: 10.1006/jmbi.2000.4397

Muza-Moons, M. M., Schneeberger, E. E., and Hecht, G. A. (2004). Enteropathogenic Escherichia coli infection leads to appearance of aberrant tight junctions strands in the lateral membrane of intestinal epithelial cells. Cell. Microbiol. 6, 783-793. doi: 10.1111/j.1462-5822.2004.00404.x

Nagai, T., Abe, A., and Sasakawa, C. (2005). Targeting of enteropathogenicEscherichia coli EspF to host mitochondria is essential for bacterial pathogenesis. J. Biol. Chem. 280, 2998-3011. doi: 10.1074/jbc.M411550200

Nguyen, Y., and Sperandio, V. (2012). Enterohemorrhagic E. coli (EHEC) pathogenesis. Front. Cell. Infect. Microbiol. 2:90. doi: 10.3389/fcimb.2012. 00090

Nobe, R., Nougayrède, J. P., Taieb, F., Bardiau, M., Cassart, D., Navarro-Garcia, F., et al. (2009). Enterohaemorrhagic Escherichia coli serogroup O111 inhibits NFB-dependent innate responses in a manner independent of a type III secreted OspG orthologue. Microbiology 155, 3214-3225. doi: 10.1099/mic.0.030759-0

Nougayrède , J.-P., and Donnenberg, M. S. (2004). Enteropathogenic Escherichia coli EspF is targeted to mitochondria and is required to initiate the mitochondrial death pathway. Cell. Microbiol. 6, 1097-1111. doi: 10.1111/j.1462-5822.2004.00421.x

Nougayrède, J.-P., Foster, G. H., and Donnenberg, M. S. (2007). Enteropathogenic Escherichia coli effector EspF interacts with host protein Abcf2. Cell. Microbiol. 9, 680-693. doi: 10.1111/j.1462-5822.2006.00820.x

Pallett, M. A., Berger, C. N., Pearson, J. S., Hartland, E. L., and Frankel, G. (2014). The type III secretion effector NleF of enteropathogenic Escherichia coli activates NF-кB early during infection. Infect. Immun. 82, 4878-4888. doi: 10.1128/IAI.02131-14

Pantaloni, D., and Carlier, M. F. (1993). How profilin promotes actin filament assembly in the presence of thymosin beta 4 . Cell 75, 1007-1014. doi: 10.1016/0092-8674(93)90544-Z

Park, J., Kim, Y., Lee, S., Park, J. J., Park, Z. Y., Sun, W., et al. (2010). SNX18 shares a redundant role with SNX9 and modulates endocytic trafficking at the plasma membrane. J. Cell Sci. 123, 1742-1750. doi: 10.1242/jcs.064170

Pawłowska, B., and Sobieszczanska, B. M. (2017). Intestinal epithelial barrier: the target for pathogenic Escherichia coli. Adv. Clin. Exp. Med. 26, 1437-1445. doi: $10.17219 /$ acem/64883

Pearson, J. S., Riedmaier, P., Marchès, O., Frankel, G., and Hartland, E. L. (2011). A type III effector protease NleC from enteropathogenic Escherichia coli targets NF-kappaB for degradation. Mol. Microbiol. 80, 219-230. doi: 10.1111/j.1365-2958.2011.07568.x

Peralta-Ramírez, J., Hernandez, J. M., Manning-Cela, R., Luna-Muñoz, J., GarciaTovar, C., Nougayréde, J. P., et al. (2008). EspF interacts with nucleationpromoting factors to recruit junctional proteins into pedestals for pedestal maturation and disruption of paracellular permeability. Infect. Immun. 76, 3854-3868. doi: 10.1128/IAI.00072-08

Petty, N. K., Bulgin, R., Crepin, V. F., Cerdeño-Tárraga, A. M., Schroeder, G. N., Quail, M. A., et al. (2009). The Citrobacter rodentium genome sequence reveals convergent evolution with human pathogenic Escherichia coli. J. Bacteriol. 192, 525-538. doi: 10.1128/JB.01144-09

Poirier, K., Faucher, S. P., Béland, M., Brousseau, R., Gannon, V., Martin, C., et al. (2008). Escherichia coli O157:H7 survives within human macrophages: global gene expression profile and involvement of the shiga toxins. Infect. Immun. 76, 4814-4822. doi: 10.1128/IAI.00446-08

Poulin, L. F., and Chamaillard, M. (2017). The battlefield in the war against attaching-and-effacing bacterial pathogens: monocytes, macrophages and dendritic cells in action. Vet. Microbiol. 202, 47-51. doi: 10.1016/j.vetmic.2016.09.007

Quitard, S., Dean, P., Maresca, M., and Kenny, B. (2006). The enteropathogenic Escherichia coli EspF effector molecule inhibits PI-3 kinase-mediated uptake independently of mitochondrial targeting. Cell. Microbiol. 8, 972-981. doi: 10.1111/j.1462-5822.2005.00680.x

Ritchie, J. M., and Waldor, M. K. (2005). The locus of enterocyte effacementencoded effector proteins all promote enterohemorrhagic Escherichia coli pathogenicity in infant rabbits. Infect. Immun. 73, 1466-1474. doi: 10.1128/IAI.73.3.1466-1474.2005

Roxas, J. L., Koutsouris, A., and Viswanathan, V. K. (2007). Enteropathogenic Escherichia coli-induced epidermal growth factor receptor activation contributes to physiological alterations in intestinal epithelial cells. Infect. Immun. 75, 2316-2324. doi: 10.1128/IAI.01690-06

Roxas, J. L., Ryan, K., Vedantam, G., and Viswanathan, V. K. (2014). EnteropathogenicEscherichia coli dynamically regulates EGFR signaling in intestinal epithelial cells. Am. J. Physiol. Gastrointest. Liver Physiol. 307, G374G380. doi: 10.1152/ajpgi.00312.2013

Ruchaud-Sparagano, M.-H., Maresca, M., and Kenny, B. (2007). Enteropathogenic Escherichia coli (EPEC) inactivate innate immune responses prior to compromising epithelial barrier function. Cell. Microbiol. 9, 1909-1921. doi: 10.1111/j.1462-5822.2007.00923.x

Runkle, E. A., and Mu, D. (2013). Tight junction proteins: from barrier to tumorigenesis. Cancer Lett. 337, 41-48. doi: 10.1016/j.canlet.2013.05.038

Sarantis, H., and Grinstein, S. (2012). Subversion of phagocytosis for pathogen survival. Cell Host Microbe 12, 419-431. doi: 10.1016/j.chom.2012.09.001

Sason, H., Milgrom, M., Weiss, A. M., Melamed-Book, N., Balla, T., Grinstein, S., et al. (2009). Enteropathogenic Escherichia coli subverts phosphatidylinositol 4,5-bisphosphate and phosphatidylinositol 3,4,5-trisphosphate upon epithelial cell infection. Mol. Biol. Cell 20, 544-555. doi: 10.1091/mbc.e08-05-0516

Sham, H. P., Shames, S. R., Croxen, M. A., Ma, C., Chan, J. M., Khan, M. A., et al. (2011). Attaching and effacing bacterial effector NleC suppresses epithelial inflammatory responses by inhibiting NF-kappaB and p38 mitogen-activated protein kinase activation. Infect. Immun. 79, 3552-3562. doi: 10.1128/IAI.05033-11

Sharma, R., Tesfay, S., Tomson, F. L., Kanteti, R. P., Viswanathan, V. K., and Hecht, G. (2006). Balance of bacterial pro- and anti-inflammatory mediators dictates net effect of enteropathogenicEscherichia coli on intestinal epithelial cells. Am. J. Physiol. Gastrointest. Liver Physiol. 290, G685-G694. doi: 10.1152/ajpgi.00404.2005

Shaw, R. K., Cleary, J., Murphy, M. S., Frankel, G., and Knutton, S. (2005). Interaction of enteropathogenic Escherichia coli with human intestinal mucosa: role of effector proteins in brush border remodeling and formation of attaching and effacing lesions. Infect. Immun. 73, 1243-1251. doi: 10.1128/IAI.73.2.1243-1251.2005

Shen, L., and Turner, J. R. (2005). Actin depolymerization disrupts tight junctions via caveolae-mediated endocytosis. Mol. Biol. Cell 16, 3919-3936. doi: 10.1091/mbc.e04-12-1089

Shen-Tu, G., Kim, H., Liu, M., Johnson-Henry, K. C., and Sherman, P. M. (2014). Protein Kinase C mediates enterohemorrhagic Escherichia coli O157:H7-induced attaching and effacing lesions. Infect. Immun. 82, 1648-1656. doi: 10.1128/IAI.00534-13

Shin, N., Ahn, N., Chang-Ileto, B., Park, J., Takei, K., Ahn, S. G., et al. (2008). SNX9 regulates tubular invagination of the plasma membrane through interaction with actin cytoskeleton and dynamin 2. J. Cell Sci. 121, 1252-1263. doi: $10.1242 /$ jcs.016709

Singh, A. P., Sharma, S., Pagarware, K., Siraji, R. A., Ansari, I., Mandal, A., et al. (2018). Enteropathogenic E. coli effectors EspF and Map independently disrupt tight junctions through distinct mechanisms involving transcriptional and post-transcriptional regulation. Sci. Rep. 8:3719. doi: 10.1038/s41598-018-22017-1

Smith, G., Carey, F. A., Beattie, J., Wilkie, M. J., Lightfoot, T. J., Coxhead, J., et al. (2002). Mutations in APC, Kirsten-ras, and p53-alternative genetic pathways to colorectal cancer. Proc. Natl. Acad. Sci. U.S.A. 99, 9433-9438. doi: $10.1073 /$ pnas. 122612899

Smythe, E., and Ayscough, K. R. (2006). Actin regulation in endocytosis. J. Cell Sci. 119, 4589-4598. doi: 10.1242/jcs.03247

Tapia, R., Kralicek, S. E., and Hecht, G. A. (2017). EPEC effector EspF promotes Crumbs3 endocytosis and disrupts epithelial cell polarity. Cell. Microbiol. 19:e12757. doi: 10.1111/cmi.12757

Touz,é, T., Hayward, R. D., Eswaran, J., Leong, J. M., and Koronakis, V. (2004). Self-association of EPEC intimin mediated by the $\beta$-barrel-containing anchor domain: a role in clustering of the Tir receptor. Mol. Microbiol. 51, 73-87. doi: 10.1046/j.1365-2958.2003.03830.x

Turner, J. R., Buschmann, M. M., Romero-Calvo, I., Sailer, A., and Shen, L. (2014). The role of molecular remodeling in differential regulation 
of tight junction permeability. Semin. Cell Dev. Biol. 36, 204-212. doi: 10.1016/j.semcdb.2014.09.022

Ugalde-Silva, P., Gonzalez-Lugo, O., and Navarro-Garcia, F. (2016). Tight junction disruption induced by type 3 secretion system effectors injected by enteropathogenic and enterohemorrhagic Escherichia coli. Front. Cell. Infect. Microbiol. 6:87. doi: 10.3389/fcimb.2016.00087

Van Itallie, C. M., and Anderson, J. M. (2014). Architecture of tight junctions and principles of molecular composition. Semin. Cell Dev. Biol. 36, 157-165. doi: 10.1016/j.semcdb.2014.08.011

Van Itallie, C. M., Fanning, A. S., Bridges, A., and Anderson, J. M. (2009). ZO-1 stabilizes the tight junction solute barrier through coupling to the perijunctional cytoskeleton. Mol. Biol. Cell 20, 3930-3940. doi: 10.1091/mbc.e09-04-0320

Viswanathan, V. K., Hodges, K., and Hecht, G. (2009). Enteric infection meets intestinal function: how bacterial pathogens cause diarrhea. Nat. Rev. Microbiol. 7, 110-119. doi: 10.1038/nrmicro2053

Viswanathan, V. K., Koutsouris, A., Lukic, S., Pilkinton, M., Simonovic, I., Simonovic, M., et al. (2004a). Comparative analysis of EspF from enteropathogenic and enterohemorrhagic Escherichia coli in alteration of epithelial barrier function. Infect. Immun. 72, 3218-3227. doi: 10.1128/IAI.72.6.3218-3227.2004

Viswanathan, V. K., Lukic, S., Koutsouris, A., Miao, R., Muza, M. M., Hecht, G., et al. (2004b). Cytokeratin 18 interacts with the enteropathogenic Escherichia coli secreted protein F (EspF) and is redistributed after infection. Cell. Microbiol. 6, 987-997. doi: 10.1111/j.1462-5822.2004.00416.x

Vogelmann, R., and Amieva, M. R. (2007). The role of bacterial pathogens in cancer. Curr. Opin. Microbiol. 10, 76-81. doi: 10.1016/j.mib.2006. 12.004

Wang, X., Du, Y., Hua, Y., Fu, M., Niu, C., Zhang, B., et al. (2017). The EspF N-terminal of enterohemorrhagic Escherichia coli O157:H7 EDL933w imparts stronger toxicity effects on HT-29 cells than the C-terminal. Front. Cell. Infect. Microbiol. 7:410. doi: 10.3389/fcimb.2017.00410

Weflen, A. W., Alto, N. M., and Hecht, G. A. (2009). Tight junctions and enteropathogenic E. coli. Ann. N. Y. Acad. Sci. 1165, 169-174. doi: 10.1111/j.1749-6632.2009.04060.x

Weflen, A. W., Alto, N. M., Viswanathan, V. K., and Hecht, G. (2010). E. coli secreted protein $\mathrm{F}$ promotes EPEC invasion of intestinal epithelial cells via an SNX9-dependent mechanism. Cell. Microbiol. 12, 919-929. doi: 10.1111/j.1462-5822.2010.01440.x

Witke, W. (2004). The role of profilin complexes in cell motility and other cellular processes. Trends Cell Biol. 14, 461-469. doi: 10.1016/j.tcb.2004.07.003

Wong, A. R., Pearson, J. S., Bright, M. D., Munera, D., Robinson, K. S., Lee, S. F., et al. (2011). Enteropathogenic and enterohaemorrhagic Escherichia coli: even more subversive elements. Mol. Microbiol. 80, 1420-1438. doi: 10.1111/j.1365-2958.2011.07661.x

Yen, H., Karino, M., and Tobe, T. (2016). Modulation of the inflammasome signaling pathway by enteropathogenic and enterohemorrhagic Escherichia coli. Front. Cell. Infect. Microbiol. 6:89. doi: 10.3389/fcimb.2016.00089

Yuhan, R., Koutsouris, A., Savkovic, S. D., and Hecht, G. (1997). Enteropathogenic Escherichia coli-induced myosin light chain phosphorylation alters intestinal epithelial permeability. Gastroenterology 113, 1873-1882. doi: 10.1016/S0016-5085(97)70006-4

Zhang, Q., Li, Q., Wang, C., Liu, X., Li, N., and Li, J. (2010). Enteropathogenic Escherichia coli changes distribution of occludin and ZO-1 in tight junction membrane microdomains in vivo. Microb. Pathog. 48, 28-34. doi: 10.1016/j.micpath.2009.10.002

Zhao, S., Zhou, Y., Wang, C., Yang, Y., Wu, X., Wei, Y., et al. (2013). The N-terminal domain of EspF induces host cell apoptosis after infection with enterohaemorrhagic Escherichia coli O157:H7. PLoS ONE 8: e55164. doi: 10.1371/journal.pone.0055164

Zihni, C., Mills, C., Matter, K., and Balda, M. S. (2016). Tight junctions: from simple barriers to multifunctional molecular gates. Nat. Rev. Mol. Cell Biol. 17, 564-580. doi: 10.1038/nrm.2016.80

Conflict of Interest Statement: The authors declare that the research was conducted in the absence of any commercial or financial relationships that could be construed as a potential conflict of interest.

Copyright (c) 2018 Hua, Yan and Wan. This is an open-access article distributed under the terms of the Creative Commons Attribution License (CC BY). The use, distribution or reproduction in other forums is permitted, provided the original author(s) and the copyright owner(s) are credited and that the original publication in this journal is cited, in accordance with accepted academic practice. No use, distribution or reproduction is permitted which does not comply with these terms. 